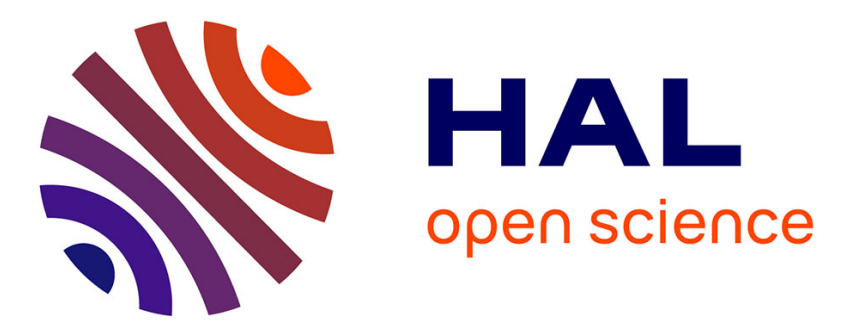

\title{
Intermediate-Term Efficacy and Tolerance of Statins in Children
}

\author{
Nathalie Mamann, Julie Lemale, Alexandra Karsenty, Béatrice Dubern, \\ Jean-Philippe Girardet, Patrick Tounian
}

\section{To cite this version:}

Nathalie Mamann, Julie Lemale, Alexandra Karsenty, Béatrice Dubern, Jean-Philippe Girardet, et al. Intermediate-Term Efficacy and Tolerance of Statins in Children. The Journal of Pediatrics, 2019, 210, pp.161 - 165. 10.1016/j.jpeds.2019.03.032 . hal-03484699

\section{HAL Id: hal-03484699 \\ https://hal.science/hal-03484699}

Submitted on 20 Dec 2021

HAL is a multi-disciplinary open access archive for the deposit and dissemination of scientific research documents, whether they are published or not. The documents may come from teaching and research institutions in France or abroad, or from public or private research centers.
L'archive ouverte pluridisciplinaire HAL, est destinée au dépôt et à la diffusion de documents scientifiques de niveau recherche, publiés ou non, émanant des établissements d'enseignement et de recherche français ou étrangers, des laboratoires publics ou privés.

\section{다)(1) $(5$}

Distributed under a Creative Commons Attribution - NonCommercial| 4.0 International 


\section{Intermediate-Term Efficacy and Tolerance of Statins in Children}

N. Mamann ${ }^{1}, M D ;$ J. Lemale ${ }^{1}$, MD; A. Karsenty ${ }^{1}, M D ; B$. Dubern $^{1}$, MD PhD; J.P. Girardet ${ }^{1}, M D ;$ P. Tounian ${ }^{1}$, MD PhD

${ }^{1}$ Pediatric Nutrition and Gastroenterology department, Trousseau Hospital, Assistance Publique-Hôpitaux de Paris, Sorbonne Université, Paris, France

Corresponding author: N. Mamann, MD, Pediatric Nutrition and Gastroenterology department, Trousseau hospital, 26 avenue du Dr. Arnold-Netter, 75012 Paris, France. Tel: +33 1447360 69. Fax: +331447362 28. E-mail: nathalie.mamann@aphp.fr

Keywords: lipid-lowering therapy; tolerability; familial hypercholesterolemia; cardiovascular risk

The authors declare no conflicts of interest. 
Objectives: To evaluate the intermediate-term efficacy and tolerance of statins in children and adolescents with familial hypercholesterolemia.

Study design: A total of 131 children or adolescents treated with statins for familial hypercholesterolemia were prospectively included. The efficacy of treatment was established by the percentage of children who achieved LDL-cholesterol levels $<160 \mathrm{mg} / \mathrm{dL}$ during treatment. Treatment tolerance was evaluated by the occurrence of clinical or laboratory side effects, regularity of increases in height and weight, and pubertal development.

Results: The median duration of treatment with statins was four years. A median decrease of $32 \%$ in LDL-cholesterol levels was observed $(P<.0001)$. The therapeutic target (LDLcholesterol $<160 \mathrm{mg} / \mathrm{dl}$ ) was achieved in $67 \%$ of cases. Increases in height and weight and sexual maturation were not affected by the treatment. Minor side effects were reported for 24 (18.4\%) patients including three cases of a clinically asymptomatic increase in CPK levels, two cases of an increase in CPK levels with muscular symptoms, 14 cases of myalgia without an increase in CPK levels, three cases of abdominal pain, one case of dysuria, and one case of diffuse pain. None of these side effects led to the discontinuation of statin therapy, although a change of statin was required in seven cases. This new statin was tolerated in all cases. No patients had abnormal liver function during treatment.

Conclusions: The results of this large cohort confirm the intermediate-term safety and efficacy of statin therapy in children with familial hypercholesterolemia. 


\section{List of abbreviations}

$A p o B=$ apolipoprotein $B-100$

$\mathrm{ALT}=$ alanine aminotransferase

AST = aspartate aminotransferase

$\mathrm{CPK}=$ creatine phosphokinase

$\mathrm{HDL}=$ high density lipoprotein

HDL-C $=$ HDL-cholesterol: cholesterol linked to high density lipoproteins

$\mathrm{LDL}=$ low density lipoprotein

LDL-C = LDL-cholesterol: cholesterol linked to low density lipoproteins

$\mathrm{N}=$ normal

PCSK9 = proprotein convertase subtilisin / kexin type 9

$\mathrm{TG}=$ triglycerides 
Familial hypercholesterolemia is one of the most common inherited diseases. It is an autosomal dominant disease which affects $1 / 200$ to $1 / 300$ people in its heterozygous form [1]. It is due to mutations in either the low density lipoprotein (LDL) receptor (LDLR), apolipoprotein B-100 (ApoB), or proprotein convertase subtilisin / kexin type 9 (PCSK9) gene, leading to elevated plasma levels of LDL cholesterol from early age and increased risk for cardiovascular disease in early adulthood [2-6]. This risk of premature cardiovascular events has prompted recommendations to lower LDL-C levels from childhood [7]. Treatment is usually based on statins (3-hydroxy-3-methylglutaryl coenzyme A reductase inhibitors), which can be initiated from the age of eight years $[8,9]$. The efficacy of statins has been widely demonstrated in adults, whether for the primary or secondary prevention of cardiovascular risk [10]. However, no studies have evaluated the efficacy of statin therapy initiated during childhood on the incidence of long-term cardiovascular events. However, it is known that statins reduce carotid intima-media thickness [11] and improve arterial endothelial function [12] in children with hypercholesterolemia.

Efficacy and good tolerance of short-term statin therapy have been widely reported in children [13]. These studies had a median duration of 24 weeks and only one lasted up to two years.

The objective of our study was to evaluate the efficacy and safety of intermediate-term statin therapy in a large cohort of children and adolescents.

\section{Methods}

All children and adolescents treated with statins for familial hypercholesterolemia between August 1992 and April 2017 in the Pediatric Nutrition and Gastroenterology Department of Trousseau Hospital were prospectively included. The diagnosis of familial hypercholesterolemia was based on 
either a causal mutation of familial hypercholesterolemia identified in the LDLR, ApoB, or PCSK9 gene, or both a LDL-C level > $190 \mathrm{mg} / \mathrm{dl}$ despite 6 months of a well-followed cholesterol-lowering diet, and a family history suggesting familial hypercholesterolemia: hypercholesterolemia in a firstdegree relative or history of early cardiovascular events (angina pectoris, myocardial infarction, percutaneous coronary intervention, coronary artery bypass, ischemic stroke, sudden cardiac death, or peripheral arterial disease) before age 55 in men and age 60 in women in a first or second degree relative. All children received advice from a dietician for the implementation of a cholesterol-lowering diet during the six months before statin therapy. According to local expert opinion, a statin was prescribed when the LDL-C level remained $>160 \mathrm{mg} / \mathrm{dl}$ in the presence of another cardiovascular risk factor (obesity, diabetes, high blood pressure, lipoprotein (a) $>500$ $\mathrm{mg} / \mathrm{l}$ ) or $>190 \mathrm{mg} / \mathrm{dl}$ in the absence of a cardiovascular risk factor. Children with homozygous familial hypercholesterolemia were excluded.

The following clinical and epidemiological data were collected for each patient: age, sex, weight, height, family history of first- or second-degree hypercholesterolemia, with or without cholesterollowering treatment, and history of early cardiovascular events in a first or second degree relative. The Waterlow score, consisting of the weight divided by the expected weight for the child's height (as a percentage), and the height divided by the expected height for the child's age (as a percentage) were used to evaluate growth [14]. Puberty was assessed by Tanner stage.

Patients were generally seen once or twice a year at follow-up. Before each consultation, a fasting lipid test was performed, including plasma TC, HDL-C, and TG levels (by enzymatic colorimetric method) and LDL-C level (calculated using the Friedewald equation). The liver enzymes aspartate aminotransferase (AST) and alanine aminotransferase (ALT) and the muscle enzyme creatinine phosphokinase (CPK) were assessed at the same time. 
The efficacy of treatment was evaluated first, by the decrease (as a percentage) in TC and LCL-C levels following statin therapy between the start of treatment and the last follow-up consultation and second, by the percentage of children who achieved an LDL-C level $<160 \mathrm{mg} / \mathrm{dl}$.

At each consultation, data on self-reported undesirable clinical effects potentially related to the treatment were collected: cramps, unexplained muscle pain, weakness or stiffness, asthenia, abdominal pain, and headache.

Biological tolerability was assessed by searching for muscle-related adverse effects, defined as a rise in CPK levels to more than five times above normal (5N). An elevation of ALT and/or AST levels to more than three times above the laboratory-defined upper limit was considered to be a sign of hepatic cytolysis.

The global tolerability of treatment was assessed by monitoring the occurrence of clinical or biological side effects, their severity, the need to change the statin, the regularity of increase in height and weight, and pubertal development. When none of these side effects occurred, we considered that statin therapy was well tolerated.

The study was approved by the local ethics committee.

Statistical analyses were performed using GraphPad Prism software (version 7.03). The Wilcoxon test, with sample matching, was used to compare clinical and laboratory measures between the start of statin therapy and the end of follow-up. Significance was set at $p<0.05$. 


\section{Results}

A total of 131 children and adolescents were included (sex ratio $=1.05)$, for whom the main characteristics are presented in Table I.

Most parents (92.3\%) were known to have hypercholesterolemia and $90.1 \%$ of

hypercholesterolemic parents were treated. A family history of early cardiovascular events was frequently found ( $69 \%$ of cases, including $14.5 \%$ first degree relatives), most involving coronary heart disease.

The diagnosis was based on targeted (family history based) screening for 121 children. For the 10 others, the lipid blood test that led to the diagnosis of hypercholesterolemia was performed for another reason: seven as part of a systematic health check, one because of the child being overweight, one for visual disorders, and one for xanthomas. Among these 10 children, nine parents did not know their lipid profile or those of their relatives and one child was adopted. The discovery of hypercholesterolemia in the children allowed the diagnosis of familial hypercholesterolemia in 6 of these 9 parents. Finally, only 3 of the 131 children (2.3\%) did not have a known family history of either first- or second-degree hypercholesterolemia or premature cardiovascular events. However, two of these three children had a family history of treated hypercholesterolemia in a third-degree relative.

Familial hypercholesterolemia was confirmed by genetic testing for 117 of the 126 children tested. All children had a heterozygous LDL receptor mutation and one child had both a heterozygous mutation of the LDL receptor and ApoB. The same mutation was sought in 64 parents with hypercholesterolemia and found for 63 . For one child, neither the mother nor father had the mutation. Among the 9 children in whom no mutation was found, 8 had 1 parent who was hypercholesterolemic (7 of whom were undergoing cholesterol-lowering therapy). 
Fifty-three children (40.5\%) were receiving another cholesterol-lowering treatment before the statin treatment: 36 received cholestyramine, 6 fibrate, 10 cholestyramine and then fibrate, and one ezetimibe.

The median age at the beginning of statin therapy was 10.0 years ( 5.2 years -17.7 years) and $25.7 \%$ of children started treatment before the age of eight years, in all cases because of early cardiovascular events in the family. Pravastatin was first prescribed for 101 patients (77\%, median age: 9.9 years [5.2-17.7]), rosuvastatin for 22 (16.8\%, median age: 9.9 years [5.9-14.2]), and atorvastatin for eight (6.1\%, median age: 12.0 years [9.6-17.2]). The statin was always started at the smallest dose. Dosages were increased to the maximum allowable dose (pravastatin : $20 \mathrm{mg}$ before age 13, $40 \mathrm{mg}$ before age 18 ; rosuvastatin $10 \mathrm{mg}$ before age $9,20 \mathrm{mg}$ before age 18 ; atorvastatin $40 \mathrm{mg}$ whatever the age); if efficacy was not within the defined criteria at the maximum allowed dose, the class of statin was changed.

The median duration of statin treatment was 48 months (2.3 months -13.3 years). Ninety-four children (71.8\%) were followed-up for more than two years. The median age at the end of followup was 14.3 years ( 6.5 years -22.5 years). At the end of the study, 26 children were still followedup. Seventy-two children were lost to follow-up after an average of 35 months, and 33 children kept being followed-up in an adult department after reaching 18 years of age. The average number of visits during follow-up was 10.4 , ie, every 8 months in average.

Children were seen for the first time, on average, 6 months after the initiation of statin treatment. At this first consultation, a median $24 \%$ decrease in LDL-C levels was observed $(p<0.0001)$. At the end of follow-up, a median $32.0 \%$ decrease in LDL-C levels was observed $(p<0.0001)$. Eighty-seven (67.4\%) of the 126 patients for whom the LDL-C levels were known at the end of follow-up achieved the therapeutic goal of an LDL-C level $<160 \mathrm{mg} / \mathrm{dl}$. The lipid profiles before statin initiation and at the end of follow-up are reported in Table II. Among the 53 children who 
received another cholesterol-lowering treatment before the statin, 8 had an LDL-C level $<160$ $\mathrm{mg} / \mathrm{dl}$, all with cholestyramine, which was replaced by a statin because cholestyramine was refused due to poor palatability. For the remaining 45 children, cholesterol-lowering treatment was replaced by a statin because LDL-C level remained $>160 \mathrm{mg} / \mathrm{dl}$.

A statin switch was necessary for 57 patients during the follow-up: in 52 cases because LDL-C levels remained $>160 \mathrm{mg} / \mathrm{dl}$ and in five cases because of side effects related to treatment. Seven children required a second switch: in two cases because of insufficient efficacy of treatment, with an LDL-C level $>160 \mathrm{mg} / \mathrm{dl}$, in two cases because of side effects, in one case to facilitate treatment (giving a single tablet instead of two), in one case in which the statin was changed by the family, and finally for 1 child because of the significant consumption of grapefruit juice while taking atorvastatin (grapefruit juice inhibits CYP 3A4, which is involved in the catabolism of atorvastatin). Three children had ezetimibe in addition to the third statin because of persistent hypercholesterolemia (LDL-C levels still > $160 \mathrm{mg} / \mathrm{dl}$ ).

Statin therapy was well tolerated by 107 (81.6\%) of the patients. Side effects occurred in 19 patients. No side effects resulted in permanent discontinuation of statin therapy. The statin had to be stopped in seven cases due to side effects, but the switch with another class of statin was well tolerated each time, without the recurrence of side effects. For the 12 remaining children, the same statin therapy was continued since their symptoms disappeared. Tolerance of the treatment is reported in Table III.

Five children required a change of statin due to clinical symptoms and / or abnormal CPK concentrations. Two others had to temporarily interrupt their treatment but were then able to resume without new side effects.

Two children taking rosuvastatin had muscle pain resulting in daily discomfort and elevated CPK levels. For the first, the symptoms occurred after four years of treatment with rosuvastatin (5 $\mathrm{mg})$. 
The CPK level was $4 \mathrm{~N}$ and spontaneously normalized when rosuvastatin was discontinued and switched to pravastatin, which was well tolerated. For the second, pain appeared one year after the start of treatment with rosuvastatin $(5 \mathrm{mg})$ and the CPK level was moderately high at $6 \mathrm{~N}$. The switch to pravastatin was well tolerated.

Three children had to temporarily discontinue statin therapy because of an isolated increase of CPK levels to $>5 \mathrm{~N}$, but without any clinical symptoms; the elevation of CPK levels was found each time during systematic blood tests. No significant physical activity in the previous days was reported. The first child was treated with rosuvastatin $(10 \mathrm{mg})$ for 6 years and the CPK level reached $24 \mathrm{~N}$. CPK spontaneously normalized within a few days after discontinuing rosuvastatin. Given the magnitude of the elevation of the CPK level, the child was switched to pravastatin, which was well tolerated with a follow-up of 18 months. The second child was treated with rosuvastatin for 22 months and had an increase in the CPK level to $6 \mathrm{~N}$ on a systematic blood test but spontaneously normalized. The continuation of rosuvastatin at a half dose $(5 \mathrm{mg}) 2$ weeks later was well tolerated. The third child showed an increase of CPK levels up to $16 \mathrm{~N}$ after being treated with pravastatin $(30 \mathrm{mg}$ ) for 3 years (the dose was increased from 20 to $30 \mathrm{mg}$ per day six months previously). Fifteen days later, the level of CPK returned to normal and treatment with pravastatin was then continued at the same dose of $30 \mathrm{mg}$ per day. CPK levels remained normal with a follow-up of 5 years.

Myalgia or cramps without an increase in CPK levels were reported for 14 children. For two, the statin was changed and resulted in the resolution of symptoms. The symptoms of the other 12 resolved spontaneously without a change of statin.

Ten children showed a transient elevation of CPK levels (but $<5 N$ ). Intense physical activity before the blood test was found in all cases. 
There were no cases of increased ALT and/or AST levels $>3 \mathrm{~N}$. Abdominal pain or intercurrent nausea was reported for three children, but the role of the statin was questionable in all cases. Transaminase levels were normal and statin therapy could be continued for each case without the recurrence of symptoms.

A case of dysuria in an adolescent girl treated with pravastatin for three years was reported. It resolved after discontinuation of pravastatin and replacement by atorvastatin. A change in treatment was also required for one child treated with rosuvastatin due to diffuse pain. However, the cause was uncertain, as there was a particular psychological context. The child did not come back to consultation after switching to pravastatin.

There was no difference in the anthropometric measures and Waterlow score before statin treatment and at the end of follow-up. No children had abnormalities of pubertal development during follow-up.

\section{Discussion}

Our study confirms the long-term efficacy and safety of statins in a large cohort of hypercholesterolemic children and adolescents followed for more than four years. There were no serious side effects requiring definitive discontinuation of statin therapy, despite muscle symptoms observed in $12.2 \%$ of patients. This confirms the lack of muscular adverse effects in children muscular on statins already reported in other studies [15-17]. In the long-term study of Braamskamp et al, only $9.3 \%$ of patients experienced muscle symptoms [15]. Indeed, the frequency of muscle symptoms in children is identical to that observed in adults, as shown by an observational study of 7,924 hyperlipidemic patients aged 18 to 75 years treated with high-dose statins, in which $10.5 \%$ of patients reported muscle symptoms [18]. This prevalence of muscle 
side effects is however higher than that reported in controlled studies in adults who experience myalgia in only 1.5 to $5 \%$ of cases [19]. This suggests that most of the clinical symptoms judged to be adverse effects of treatment are probably not related to statin use. The European Atherosclerosis Society (EAS) recommends measuring CPK levels before the initiation of statin therapy and thereafter only if there are muscle symptoms during treatment [20]. However, a consensus of French experts on the pediatric use of statins recommends clinical and biological monitoring (transaminases and $\mathrm{CPK}$ ) one to three months after the start of statin treatment and then at least once every year [21]. Our results support the European and American recommendation of assessing muscle enzymes in statin-treated children only if there are muscle symptoms.

There were no cases of statin-related liver damage in our study. This confirms the very good hepatic tolerance of statins already described in many randomized studies in children $[13,22,23]$. However, recommendations for the monitoring of liver enzymes in children with statin therapy are stricter than those for muscle enzymes. The EAS recommends systematically measuring ALT and AST levels before the initiation of statin therapy, every three months if there is a history of liver disease or, more frequently, if levels rise 3-fold greater than the upper limit of normal and of course if there are clinical symptoms of hepatotoxicity [20]. In France, the recommendations are to measure ALT and AST levels one to three months after beginning statin treatment and then at least once a year in the absence of clinical symptoms [21]. We believe that although hepatic complications related to statins are exceptional, their potential seriousness warrants systematic monitoring of transaminases.

Our results confirm that statins significantly decrease plasma LDL-C levels in children. The decrease in LDL-C levels between the initiation of statin treatment and the end of follow-up 
$(-32.0 \%)$ was similar to that obtained in randomized controlled studies (- 20 to $40 \%)[8,13]$.

Although some studies have reported a significant increase in HDL-C levels with statins [23], we did not find any significant increase in HDL-C, but a small significant decrease in HDL-C levels. In our study, the therapeutic goal for LDL-cholesterol reduction was achieved in $67.4 \%$ of cases. We applied the objective proposed by French experts, who recommend achieving an LDL-C level < $160 \mathrm{mg} / \mathrm{dl}$ in patients up to 20 years of age [21]. However, the EAS recommends achieving an LDLC level $<135 \mathrm{mg} / \mathrm{dl}$ [24], close to US guidelines that set a target LDL-C level of $<130 \mathrm{mg} / \mathrm{dL}$ or $<$ $110 \mathrm{mg} / \mathrm{dL}$ in the presence of a family history of early cardiovascular events [25]. This is an area for future research as the benefit of different levels of reduction in LDL-C during childhood in preventing cardiovascular events in adulthood is still uncertain [8].

Our study had several limitations. It was a relatively small and single center study. Because clinical side effects were self-reported by the children, we cannot exclude they could have been either over- or under-estimated. Although the growth of our patients was normal, the absence of a control group did not allow us to confirm that the treatment did not have any impact on growth. The average follow-up of our study was longer than that of most studies published until now $[12,13,18,23]$. However, undesirable effects that may occur after several decades of treatment cannot be ruled out. Further studies are necessary to assess the putative side effects that could appear after several decades of treatment. 


\section{Bibliographie}

[1] Pang J, Martin AC, Mori TA, Beilin LJ, Watts GF. Prevalence of Familial Hypercholesterolemia in Adolescents: Potential Value of Universal Screening? J Pediatr 2016;170:315-6.

[2] Futema M, Plagnol V, Li K, Whittall RA, Neil HAW, Seed M, et al. Whole exome sequencing of familial hypercholesterolaemia patients negative for $L D L R$ / $A P O B$ / PCSK9 mutations. J Med Genet 2014;51:537-44.

[3] Morrison KM, Dyal L, Conner W, Helden E, Newkirk L, Yusuf S, et al. Cardiovascular risk factors and non-invasive assessment of subclinical atherosclerosis in youth. Atherosclerosis 2010;208:501-5.

[4] Aggoun Y, Bonnet D, Sidi D, Girardet JP, Brucker E, Polak M, et al. Arterial mechanical changes in children with familial hypercholesterolemia. Arterioscler Thromb Vasc Biol 2000;20:2070-5.

[5] Wiegman A, de Groot E, Hutten BA, Rodenburg J, Gort J, Bakker HD, et al. Arterial intima-media thickness in children heterozygous for familial hypercholesterolaemia. Lancet Lond Engl 2004;363:369-70.

[6] Stone NJ, Levy RI, Fredrickson DS, Verter J. Coronary Artery Disease in 116 Kindred with Familial Type II Hyperlipoproteinemia. Circulation 1974;49:476-88.

[7] McCrindle BW, Urbina EM, Dennison BA, Jacobson MS, Steinberger J, Rocchini AP, et al. Drug therapy of high-risk lipid abnormalities in children and adolescents: a scientific statement from the American Heart Association Atherosclerosis, Hypertension, and Obesity in Youth Committee, Council of Cardiovascular Disease in the Young, with the Council on Cardiovascular Nursing. Circulation 2007;115:1948-67.

[8] Lozano P, Henrikson NB, Dunn J, Morrison CC, Nguyen M, Blasi PR, et al. Lipid Screening in Childhood and Adolescence for Detection of Familial Hypercholesterolemia: Evidence Report and Systematic Review for the US Preventive Services Task Force. JAMA 2016;316:645-55.

[9] Daniels SR, Gidding SS, de Ferranti SD, National Lipid Association Expert Panel on Familial Hypercholesterolemia. Pediatric aspects of familial hypercholesterolemias: recommendations from the National Lipid Association Expert Panel on Familial Hypercholesterolemia. J Clin Lipidol 2011;5:S30-37.

[10] Ford I, Murray H, Packard CJ, Shepherd J, Macfarlane PW, Cobbe SM, et al. Long-term follow-up of the West of Scotland Coronary Prevention Study. N Engl J Med 2007;357:1477-86.

[11] Rodenburg J, Vissers MN, Wiegman A, van Trotsenburg ASP, van der Graaf A, de Groot E, et al. Statin treatment in children with familial hypercholesterolemia: the younger, the better. Circulation 2007;116:664-8. 
[12] Wiegman A, Hutten BA, de Groot E, Rodenburg J, Bakker HD, Büller HR, et al. Efficacy and safety of statin therapy in children with familial hypercholesterolemia: a randomized controlled trial. JAMA 2004;292:331-7.

[13] Vuorio A, Kuoppala J, Kovanen PT, Humphries SE, Tonstad S, Wiegman A, et al. Statins for children with familial hypercholesterolemia. Cochrane Database Syst Rev 2017;7:CD006401.

[14] Waterlow JC. Classification and definition of protein-calorie malnutrition. Br Med J 1972;3:566-9.

[15] Braamskamp MJAM, Kusters DM, Avis HJ, Smets EMA, Wijburg FA, Kastelein JJP, et al. Long-Term Statin Treatment in Children with Familial Hypercholesterolemia: More Insight into Tolerability and Adherence. Pediatr Drugs 2015;17:159-66.

[16] Johnson PK, Mendelson MM, Baker A, Ryan HH, Warren S, Graham D, et al. StatinAssociated Myopathy in a Pediatric Preventive Cardiology Practice. J Pediatr 2017;185:94-98.e1.

[17] Carreau V, Girardet J-P, Bruckert E. Long-term follow-up of statin treatment in a cohort of children with familial hypercholesterolemia: efficacy and tolerability. Paediatr Drugs 2011;13:267-75.

[18] Bruckert E, Hayem G, Dejager S, Yau C, Bégaud B. Mild to moderate muscular symptoms with high-dosage statin therapy in hyperlipidemic patients--the PRIMO study. Cardiovasc Drugs Ther 2005;19:403-14.

[19] Thompson PD. Statin-Associated Myopathy. JAMA 2003;289:1681.

[20] Wiegman A, Gidding SS, Watts GF, Chapman MJ, Ginsberg HN, Cuchel M, et al. Familial hypercholesterolaemia in children and adolescents: gaining decades of life by optimizing detection and treatment. Eur Heart J 2015;36:2425-37.

[21] Girardet J-P, Luc G, Rieu D, Bruckert E, Darmaun D, Farnier M, et al. [Recommendations for children with hypercholesterolemia]. Arch Pediatr Organe Off Soc Francaise Pediatr 2011;18:217-29.

[22] Kusters DM, Avis HJ, de Groot E, Wijburg FA, Kastelein JJP, Wiegman A, et al. Tenyear follow-up after initiation of statin therapy in children with familial hypercholesterolemia. JAMA 2014;312:1055-7.

[23] Arambepola C, Farmer AJ, Perera R, Neil H a. W. Statin treatment for children and adolescents with heterozygous familial hypercholesterolaemia: a systematic review and meta-analysis. Atherosclerosis 2007;195:339-47.

[24] Developed with the special contribution of: European Association for Cardiovascular Prevention \& Rehabilitation, Authors/Task Force Members, Reiner Z, Catapano AL, De Backer G, Graham I, et al. ESC/EAS Guidelines for the management of dyslipidaemias: The Task Force for the management of dyslipidaemias of the European Society of Cardiology (ESC) and the European Atherosclerosis Society (EAS). Eur Heart J 2011;32:1769-818. 
[25] Expert Panel on Integrated Guidelines for Cardiovascular Health and Risk Reduction in Children and Adolescents, National Heart, Lung, and Blood Institute. Expert panel on integrated guidelines for cardiovascular health and risk reduction in children and adolescents: summary report. Pediatrics 2011;128 Suppl 5:S213-256. 
Table I. Characteristics of the 131 children studied.

\begin{tabular}{|c|c|c|}
\hline & $\operatorname{Sex}[\mathrm{n}(\%)]$ & M: 67 (51.1) / F: 64 (48.9) \\
\hline & $\begin{array}{l}\text { First-degree history: } \\
\text { parental history of hypercholesterolemia } \\
\text { undetermined }\end{array}$ & $\begin{array}{ll}\text { - } & 121(92.3) \\
\text { - } \quad 10(7.6)\end{array}$ \\
\hline & $\begin{array}{l}\text { Lipid-lowering therapy in a first-degree } \\
\text { relative }\end{array}$ & $109(83.2)$ \\
\hline & $\begin{array}{l}\text { Early cardiovascular disease in a first or } \\
\text { second-degree relative }[n=126(\%)]\end{array}$ & $87(69.0)$ \\
\hline & Diagnosis with targeted screening [n (\%)] & $121(92.3)$ \\
\hline & Age at diagnosis [mean (min-max)] & $\begin{array}{l}6.8 \text { years (12 months }-14.4 \\
\text { years) }\end{array}$ \\
\hline - & $\begin{array}{l}\text { Genetic testing of children } \\
\text { ( } n=126) \text { : } \\
\text { LDLR mutation } \\
\text { ApoB mutation } \\
\text { PCSK9 mutation } \\
\text { no mutation found }\end{array}$ & $\begin{array}{ll}\text { - } & 117 \\
\text { - } & 1^{*} \\
\text { - } & 0 \\
\text { - } & 9\end{array}$ \\
\hline - & $\begin{array}{l}\text { Genetic testing of parents } \\
(\mathrm{n}=64) \text { : } \\
\text { Same mutation in one of the parents } \\
\text { No mutation in parents }\end{array}$ & - 63 \\
\hline
\end{tabular}

*One child had both LDLR and Apo B mutations

Abbreviations: LDLR, Low Density Lipoprotein Receptor; ApoB, Apolipoprotein B-100; PCSK9, Proprotein Convertase Subtilisin / Kexin type 9 
Table II. Lipid balance before the initiation of statin treatment and at the end of follow-up. Results are expressed as the median (min-max).

\begin{tabular}{|l|c|c|c|c|}
\hline & $\begin{array}{c}\text { Before statin } \\
\text { therapy }\end{array}$ & $\begin{array}{c}\text { With statin, at the } \\
\text { end of follow-up }\end{array}$ & $\begin{array}{c}\text { Percentage } \\
\text { difference }\end{array}$ & $p$ \\
\hline TC (mg/dl) (n= 126) & $283(190-472)$ & $214(124-376)$ & $-24.4 \%$ & $<0.0001$ \\
\hline $\begin{array}{l}\text { LDL-C (mg/dl) (n }= \\
\text { 126) }\end{array}$ & $209(117-413)$ & $142(45-295)$ & $-32.0 \%$ & $<0.0001$ \\
\hline HDL-C (mg/dl) (n= & $58(26-119)$ & $54.5(27-101)$ & $-6.0 \%$ & 0.0025 \\
\hline $\mathbf{1 2 2})$ & $61(23-165)$ & $60(25-229)$ & $-1.6 \%$ & 0.8 \\
\hline TG (mg/dl) (n= 122) & & & & \\
\hline
\end{tabular}

Abbreviations: TC, total cholesterol; HDL-C, cholesterol linked to high-density lipoproteins; LDL-C, cholesterol linked to low-density lipoproteins; TG, triglycerides 
Table III. Tolerance of statin therapy in 131 children.

\begin{tabular}{|c|c|}
\hline Tolerance of the statin & n (\%) \\
\hline No side effects & $107(81.6)$ \\
\hline Muscular side effect: & 19 (14.5\%) \\
\hline - Asymptomatic increase of CPK $>5 \mathrm{~N}$ & - 3 \\
\hline $\begin{array}{l}\text { - Increase of CPK level with muscular } \\
\text { symptoms }\end{array}$ & - 2 \\
\hline $\begin{array}{l}\text { - Muscular symptoms without an increase } \\
\text { in CPK }\end{array}$ & - 14 \\
\hline Hepatic side effect: & 0 \\
\hline - Increase of AST or ALT > $3 \mathrm{~N}$ & - 0 \\
\hline Other reported side effects: & 5 \\
\hline - Dysuria & - 1 \\
\hline - Diffuse pain & - 1 \\
\hline - Abdominal pain & - 3 \\
\hline Statin switch because of side effect & $7(5.3)$ \\
\hline \multicolumn{2}{|l|}{ Statural growth and weight gain $(N=124)$} \\
\hline $\begin{array}{l}\text { - Weight / ideal weight for height before } \\
\text { treatment }\end{array}$ & - $\quad 103.9 \%$ \\
\hline $\begin{array}{l}\text { - Weight / ideal weight for height at the } \\
\text { end of follow-up }\end{array}$ & - $104.2 \%$ \\
\hline $\begin{array}{l}\text { - Height / height expected for age before } \\
\text { treatment }\end{array}$ & - $101.4 \%$ \\
\hline $\begin{array}{l}\text { - Height / height expected for age at the } \\
\text { end of follow-up }\end{array}$ & - $101.6 \%$ \\
\hline
\end{tabular}

